\title{
Optimisation of the extraction process of antioxidant capacity compounds from beet (Beta vulgaris L.) stalk
}

\section{Otimização do processo de extração de compostos com capacidade antioxidante do talo de beterraba (Beta vulgaris $L_{\text {.) }}$}

\author{
Emanueli Backes ${ }^{1}$; Aziza Kamal Genena ${ }^{2 *}$
}

\section{Highlights:}

RSM is an efficient and useful tool for extraction process optimization.

Beet stalk is a potential source of recovery for natural antioxidant compounds.

Beet stalk showed antioxidant capacity superior to other agri-food residues.

\begin{abstract}
Beet is a traditional root consumed worldwide and is considered a potential source of several bioactive compounds, yet during production and commercialisation activities, its leaves and stalks are discarded. The beet residue has notable quantities of diverse phenolic compounds that are not taken advantage of it. The beet stalks (sample) were obtained from a local producer at the municipality of Marechal Cândido Rondon, Paraná state, Brazil. The optimisation of the extraction process of antioxidant capacity compounds from beet stalk was done by response surface methodology (RSM), with three independent variables (time, from 5 to $85 \mathrm{~min}$; temperature, from 20 to $80{ }^{\circ} \mathrm{C}$ and solvent, from 0 to $100 \%$ of ethanol/ water ratio). Extracts were evaluated for their reducing capacity, measured by the Folin-Ciocalteu method, and antioxidant capacity by the ability to scavenge DPPH and ABTS free radicals. The optimal global extraction conditions determined were $5 \mathrm{~min}, 80^{\circ} \mathrm{C}$ and $50 \%$ ethanol, yielding $13.157 \mathrm{mg}$ gallic

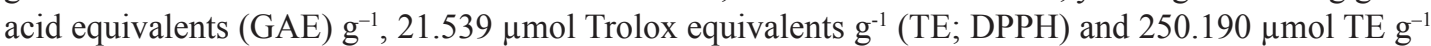
(ABTS). Beet stalk demonstrated to be an alternative and rich source of recovering of natural antioxidant compounds, showing higher contents when compared to other agro-industrial residues.
\end{abstract}

Key words: ABTS method. DPPH method. Natural antioxidant. Response surface methodology. Reducing capacity.

\section{Resumo}

\begin{abstract}
A beterraba é uma raiz tradicionalmente consumida em todo mundo e reportada como fonte de diversos compostos bioativos, porém, em atividades de processamento e comercialização, tem suas folhas e talos descartados. O resíduo de beterraba possui quantidades notáveis de compostos bioativos que não são aproveitados. Os talos de beterraba (amostra) foram obtidas de produtor local do município de Marechal Cândido Rondon, Paraná, Brasil. A otimização do processo de extração de compostos com capacidade antioxidante do talo da beterraba foi realizada por metodologia de superfície de resposta (MSR) utilizando três variáveis independentes (tempo, de 5 a $85 \mathrm{~min}$; temperatura, de 20 a $80{ }^{\circ} \mathrm{C}$ e solvente, de 0 a $100 \%$ de etanol/água). Os extratos foram avaliados quanto a sua capacidade redutora, avaliada pelo método Folin-Ciocalteu, e capacidade antioxidante avaliada pela sua habilidade em sequestrar os

\footnotetext{
1 Discente do Curso de Graduação em Engenharia de Alimentos, Universidade Tecnológica Federal do Paraná, UTFPR, Medianeira, PR, Brasil. E-mail: emanuelibackes@outlook.com

2 Prof $^{\mathrm{a}} \mathrm{Dr}^{\mathrm{a}}$, Departamento Acadêmico de Alimentos, UTFPR, Medianeira, PR, Brasil. E-mail: azizakg@utfpr.edu.br

* Author for correspondence
} 
radicais livres DPPH e ABTS. As condições ótimas globais determinadas foram $5 \mathrm{~min}, 80^{\circ} \mathrm{C}$ e $50 \%$ de etanol, que produziram valores de: 13,157 mg equivalente de ácido gálico (EAG) $\mathrm{g}^{-1}, 21,539 \mu \mathrm{mol}$ de equivalente Trolox g-1 (ET; DPPH) e 250,190 $\mu \mathrm{mol} \mathrm{ET} \mathrm{g}^{-1}$ (ABTS). O talo de beterraba demonstrou ser uma alternativa e rica fonte de recuperação de compostos antioxidantes naturais apresentando maiores teores quando comparado a outros resíduos agroindustriais.

Palavras-chave: Antioxidantes naturais. Método DPPH. Método ABTS. Metodologia de superfície de resposta. Capacidade redutora.

\section{Introduction}

Oxidation reactions are responsible for several deleterious effects on health and food quality. The oxidative process results from chemicallyunstable compounds called free radicals. The use of antioxidants effectively alleviates oxidative damage by mitigating free radical-mediated processes (Lemes, Álvares, Egea, Brandelli, \& Kalil, 2016).

As a result of industrial activities, thousands of tons of unused or low-value waste are generated daily, causing economic losses and adverse environmental impacts (Costa, Hermes, Rios, \& Flôres, 2017). This residual material has been recognised as a natural source of several bioactive compounds associated with health benefits, such as the ability to retard the development of cardiovascular disease, cancer, and inflammatory diseases. In this sense, food industry waste provides unique opportunities to transform these substrates into high added-value nutritional and commercial ingredients as an integrative process towards sustainability (Biondo et al., 2014; Costa et al., 2017). Besides conferring health benefits, natural antioxidants are considered safe for human and animal consumption (Ahmadian-Kouchaksaraie \& Niazmand, 2017; Tran, Athanassiou, Basit, \& Bayer, 2017). In contrast, synthetic antioxidants have been linked to long-term health issues and cancerpromoting action (Ahmadian-Kouchaksaraie \& Niazmand, 2017).

Beet (Beta vulgaris L.) is a traditional root consumed worldwide that originated in North Africa but is cultivated in temperate climates in several regions of the world. Beet has bioactive and functional characteristics due to the presence of compounds, such as carotenoids, polyphenols, and flavonoids, in addition to fibre (Costa et al., 2017; Nistor, Seremet, Andronoiu, Rudi, \& Botez, 2017). Some of these constituents are of notable presence in beet, like the betalains, which confer beet's characteristic colour and are known to have antioxidant capacity (Tran et al., 2017; Kumar, Kushwaha, Goyal, Tanwar, \& Kaur, 2018).

In processing and marketing activities, beets are separated from stalks and leaves, which are discarded and used as organic fertiliser or animal feed. Although beet residue contains notable quantities of diverse phenolic compounds, the lack of knowledge about the nutritional value of these residues and the eating habits of the population leads to the non-utilisation of an abundant source of natural antioxidants (Biondo et al., 2014).

The extraction of bioactive compounds from natural matrices allows for their further separation and characterisation. To maximise the recuperation and quality of the compound(s) of interest, the extraction variables, such as the method, solvent of extraction and extraction conditions must be considered in the context of the destination of the target material, economics of the process, environmental repercussions of the extraction process and efficient utilisation of resources (Ilaiyaraja, Likhith, Babu, \& Khanum, 2015; Altemimi, Lakhssassi, Baharlouei, Watson, \& Lightfoot, 2017).

Response surface methodology (RSM) is a collection of statistical and mathematical techniques used for process optimisation and modelling. This tool is very useful in many areas of plant research and operation, as it allows determining the 
conditions that lead to maximum response (Ameer et al., 2017; Backes et al., 2018).

The present study aimed to optimise the extraction conditions of compounds with antioxidant capacity from beet stalk(BS). For that purpose, the joint effect of the identified relevant variables was described through RSM. The extracts were evaluated for their reducing capacity, measured by the Folin-Ciocalteu method, and antioxidant capacity by DPPH and $\mathrm{ABTS}^{+}$methods.

\section{Material and Methods}

Sample, standards, and reagents

The beet stalks (TB) were obtained from a local producer at the municipality of Marechal Cândido Rondon, Paraná state, Brazil. The stalks were sanitized, separated from the leaves, dried at $40 \pm$ $1{ }^{\circ} \mathrm{C}$ (Incubator NI-1705, Bunker, Piracicaba, SP, Brazil) to constant weight and ground in a 30 mesh sieve knife mill (SL31, Solab, Piracicaba, SP, Brazil). The sample was kept frozen at $-18 \pm 1{ }^{\circ} \mathrm{C}$ until use.

$\mathrm{DPPH} \cdot \quad$ (2,2-diphenyl-1-picrylhydrazyl), ABTS $^{\bullet^{+}} \quad\left(2,2^{\prime}\right.$-Azino-bis(3-ethylbenzothiazoline6-sulfonic acid)) and Trolox (6-Hydroxy-2,5,7,8tetramethylchromane-2-carboxylic acid) were acquired from Sigma-Aldrich. Gallic acid, FolinCiocalteu reagent and grade PA ethyl alcohol were acquired from Dynamics. Absolute anhydrous sodium carbonate was acquired from Anhydrol and potassium persulfate from Cinética.

Description of the extraction conditions and associated relevant variables

The extraction technique used was heat-assisted extraction, also known as maceration, and the relevant independent variables in this process were defined based on preliminary studies (Albuquerque et al., 2017; Backes et al., 2018). These variables were time $(t)$, extraction temperature $(T)$, and extraction solvent proportion $(S$, ethanol/water ratio). For all assays, the extract concentration was maintained at $100 \mathrm{~g} \mathrm{~L}^{-1}$.

Dry TB samples $(4 \mathrm{~g})$ were extracted with 40 $\mathrm{mL}$ of solvent (ethyl alcohol) in a double-jacket reservoir and coupled to a thermostated bath (TE184, Tecnal, Piracicaba, SP, Brazil) for temperature control. The extract was kept under stirring and protected from light. The variables and intervals studied were $t$ (X1; 5 to $85 \mathrm{~min}), T$ (X2;20 to 80 $\left.{ }^{\circ} \mathrm{C}\right)$, and $S$ (X3; 0 to $\left.100 \%\right)$.

The resulting extracts were centrifuged (refrigerated centrifuge; CT 5000-R, Cquímica, Fortaleza, CE, Brazil; $600 \mathrm{rpm}$; $15 \mathrm{~min}$ ) and filtered through filter paper (Whatman $n^{\circ} 4$ ) to remove suspended solids. The tests were performed to evaluate the RC and antioxidant capacity of the extracts to determine the extraction conditions that maximise these results.

\section{Experimental design and mathematical model}

The combined effect of the three selected independent variables $(t: X 1, T: X 2$ and $S: X 3)$ was analysed using a rotational central composite design. The design combined the different levels to obtain eight factorial tests, six axial points, and three repetitions in the central point, totalling 17 tests in total. The range of value of the variables is presented in Table 1.

The RSM data were fitted by a least-squares calculation using the following second-order polynomial equation (Equation 1).

$$
Y=\beta_{0}+\sum_{i=1}^{n} \beta_{1} X_{1}+\sum_{\substack{i=1 \\ j>i}}^{n-1} \sum_{j=2}^{n} \beta_{j} X_{i} X_{j}+\sum_{i=1}^{n} \beta_{i} X_{i}^{2}
$$

where $Y$ is the dependent variable (response; changes in each antioxidant capacity method) to be modelled, $X_{i}$ and $X_{j}$ define the independent variables, $\beta_{0}$ is the constant coefficient (mean), $\beta_{i}$ is the coefficient of linear effect, $\beta_{i j}$ is the coefficient of interaction effect, $\beta_{i i}$ is the coefficient of quadratic effect, and $n$ is the number of variables. 
Table 1

Matrix with coded and natural values for the three independent variables used at rotational central composite design

\begin{tabular}{cccc}
\hline \multirow{2}{*}{ Codded values } & \multicolumn{3}{c}{ Natural values } \\
\cline { 2 - 4 } & $X 1(\mathrm{~min})$ & $X 2\left({ }^{\circ} \mathrm{C}\right)$ & $X 3(\%)$ \\
\hline-1.68 & 5 & 20 & 0 \\
-1 & 21.2 & 32.14 & 20.3 \\
0 & 45 & 50 & 50 \\
1 & 68.8 & 67.86 & 79.9 \\
1.68 & 85 & 80 & 100 \\
\hline
\end{tabular}

The data obtained were analysed with the Statistica 7.0 software (Statsoft Inc., Tulsa, OK, USA), which was also used to generate the 3D response surface plots. The statistical significance of the effect of the independent variable was evaluated by Student's t-Test $(\alpha=0.05)$. The effects considered non-significant ( $p$-value $>0.05$ ) were not used for the generation of the mathematical models. The statistical significance of the models was evaluated by Fisher's F-test $(\alpha=0.05)$ on the analysis of variance (ANOVA). The Tukey test at $95 \%$ of confidence interval was used to evaluate the differences among the means.

\section{Reducing capacity (RC)}

The extracts $\mathrm{RC}$ was evaluated by the content of reducing substances of Folin-Ciocalteu reagent, a usual method used to measure the total phenolic content. According to the procedure described by Ainsworth and Gillespie (2007), in the absence of light and at room temperature, $1 \mathrm{~mL}$ of $20 \%$ FolinCiocalteu reagent and $4 \mathrm{~mL}$ of $700 \mathrm{mM}$ sodium carbonate were added to a tube containing 500 $\mu \mathrm{L}$ of extract. Ethyl alcohol was used to replace the extract in the blank. After $2 \mathrm{~h}$ of reaction at room temperature and in the dark, the absorbance was measured at $765 \mathrm{~nm}$ in a spectrophotometer (DR2700, Hach, Loveland, CO, USA). The RC of each extract was obtained from an analytical curve prepared with gallic acid ( 5 to $100 \mu \mathrm{g} \mathrm{mL}^{-1}$ ), and the results were expressed as milligrams of gallic acid equivalents (GAE) per gram of sample.

Pearson's correlation test was performed to evaluate the correlation between $\mathrm{RC}$ and each antioxidant capacity method values. Student's T-test $(\alpha=0.05)$ was used to analyse the correlation significance.

\section{DPPH•method}

The DPPH antioxidant capacity of the extracts was determined as described by Mensor et al. (2001), combining $2.5 \mathrm{~mL}$ of the extract with $1.0 \mathrm{~mL}$ of 0.3 $\mathrm{mM}$ DPPH solution. Absorbance was measured at $518 \mathrm{~nm}$ after $30 \mathrm{~min}$ of reaction at room temperature in the dark. Ethanol $(1.0 \mathrm{~mL})$ was added to the extract solution $(2.5 \mathrm{~mL})$ as the blank, and DPPH $(1.0 \mathrm{~mL} ; 0.3 \mathrm{mM})$ solution added with ethanol (2.5 $\mathrm{mL}$ ) was used as a control. The measured values were converted to $\mathrm{DPPH}$ - inhibition percentage $(I P \%)$, according to Equation 2.

$\boldsymbol{I P} \%=100-\left[\frac{\left(A b s_{\text {sample }}-A b s_{\text {blank }}\right) \times 100}{A b s_{\text {control }}}\right]$

The DPPH inhibition percentage of each extract was obtained and the values were converted into micromoles of Trolox equivalents (DPPH) per gram of sample through the analytical curve constructed for Trolox (100 to $2000 \mu \mathrm{M}$ ). 


\section{ABTS $\bullet^{+}$method}

The ABTS $\bullet^{+}$antioxidant capacity of the extracts was conducted according to the assay described by Re, Pellegrini, Proteggente, Pannala and RiceEvans (1999). An aqueous solution of the $7 \mathrm{mM}$ ABTS radical was prepared from ABTS ${ }^{+}$stock solution with potassium persulphate $(2.45 \mathrm{mM})$. In the absence of light and at room temperature, the solution was left for 12 to $16 \mathrm{~h}$ to generate ABTS $\bullet^{+}$. Ethanol was added to the solution until an absorbance of $0.700 \pm 0.020$ at $734 \mathrm{~nm}$. After combining $50 \mu \mathrm{L}$ of the extract with $5 \mathrm{~mL}$ of ABTS $\bullet^{+}$ solution, the mixture was left for $6 \mathrm{~min}$, and then the absorbance read at $734 \mathrm{~nm}$. For the blank, $50 \mu \mathrm{L}$ of ethanol was used instead of the extract. ABTS $\bullet^{+}$ inhibition percentage $(I P \%)$ was determined by Equation 3. Trolox-equivalent antioxidant capacity was determined from an analytical curve of Trolox by converting the inhibition percentage values obtained. The results were expressed as micromoles of Trolox equivalents per gram of sample (ABTS).

$\boldsymbol{I P} \%=\left(1-\frac{A b s_{\text {sample }}}{A b s_{\text {blank }}}\right) \times 100$

\section{Results and Discussion}

Development of mathematical models with RSM application

The RC of the extracts obtained under different extraction conditions and their ability to scavenger the DPPH and ABTS radicals were evaluated (Table 2 ). The very similar values observed in tests 15,16 , and 17 (central point repetitions of the experimental design) in the three evaluated methods show good repeatability of the presented data.

The $\mathrm{RC}$ values varied according to the extraction conditions applied, with values from 3.088 to 13.377 mg GAE $\mathrm{g}^{-1}$. The same behaviour was identified in the ability of the extract to sequester ABTS •+, presenting ABTS values of 77.838 to 250.551 $\mu$ mol Trolox $\mathrm{g}^{-1}$. This trend (variation of response according to extraction condition) was not observed in the DPPH data, with values ranging from 21.610 to $22.460 \mu \mathrm{mol}$ Trolox $\mathrm{g}^{-1}$ only.

Table 2

Rotational central composite design for the optimization of the independent variables $(X 1, X 2$, and $X 3)$ and their response functions (RC, DPPH and ABTS)

\begin{tabular}{ccccccc}
\hline Run & $X 1$ & $X 2$ & $X 3$ & $\begin{array}{c}\text { RC } \\
\left(\mathrm{mg} \mathrm{GAE} \mathrm{g}^{-1}\right)\end{array}$ & $\begin{array}{c}\text { DPPH } \\
\left(\mu \mathrm{mol} \mathrm{Trolox} \mathrm{g}{ }^{-1}\right)\end{array}$ & $\begin{array}{c}\text { ABTS } \\
\left(\mu \mathrm{mol} \mathrm{Trolox} \mathrm{g}^{-1}\right)\end{array}$ \\
\hline 1 & -1 & -1 & -1 & $9.869 \pm 0.423$ & $21.647 \pm 0.066$ & $184.846 \pm 1.120$ \\
2 & 1 & -1 & -1 & $9.329 \pm 0.682$ & $21.610 \pm 0.213$ & $174.732 \pm 1.354$ \\
3 & -1 & 1 & -1 & $11.214 \pm 0.567$ & $22.425 \pm 0.182$ & $210.038 \pm 1.936$ \\
4 & 1 & 1 & -1 & $10.976 \pm 0.140$ & $21.625 \pm 0.124$ & $205.580 \pm 2.818$ \\
5 & -1 & -1 & 1 & $9.862 \pm 0.355$ & $22.022 \pm 0.008$ & $144.715 \pm 1.291$ \\
6 & 1 & -1 & 1 & $8.802 \pm 0.816$ & $22.040 \pm 0.108$ & $134.861 \pm 1.131$ \\
7 & -1 & 1 & 1 & $11.343 \pm 0.463$ & $22.074 \pm 0.034$ & $212.454 \pm 1.361$ \\
8 & 1 & 1 & 1 & $9.568 \pm 0.124$ & $21.880 \pm 0.050$ & $200.209 \pm 1.711$ \\
9 & -1.68 & 0 & 0 & $10.629 \pm 0.548$ & $21.913 \pm 0.198$ & $199.081 \pm 1.959$ \\
10 & 1.68 & 0 & 0 & $9.573 \pm 0.271$ & $21.727 \pm 0.075$ & $179.302 \pm 1.936$ \\
11 & 0 & -1.68 & 0 & $9.720 \pm 0.333$ & $21.671 \pm 0.034$ & $122.056 \pm 1.293$ \\
12 & 0 & 1.68 & 0 & $13.377 \pm 0.280$ & $21.857 \pm 0.412$ & $250.551 \pm 1.801$ \\
13 & 0 & 0 & -1.68 & $8.329 \pm 0.463$ & $22.460 \pm 0.148$ & $126.002 \pm 1.711$
\end{tabular}


continuation

\begin{tabular}{ccccccc}
14 & 0 & 0 & 1.68 & $3.088 \pm 0.463$ & $22.209 \pm 0.226$ & $77.838 \pm 1.120$ \\
15 & 0 & 0 & 0 & $9.873 \pm 0.450$ & $21.694 \pm 0.266$ & $173.921 \pm 2.262$ \\
16 & 0 & 0 & 0 & $9.207 \pm 0.334$ & $21.876 \pm 0.263$ & $172.447 \pm 2.581$ \\
17 & 0 & 0 & 0 & $9.325 \pm 0.225$ & $21.777 \pm 0.236$ & $174.657 \pm 2.963$ \\
\hline
\end{tabular}

A correlation coefficient was obtained between $\mathrm{RC}$ and DPPH results, and of between RC and ABTS ones. No correlation between RC and DPPH values was observed, but a strong and significant correlation $(r=0.867)$ was obtained between RC and ABTS values. It indicates an upward trend of the antioxidant capacity measured through the ABTS ${ }^{+}$ method when the content of phenolic compounds increases.

Since the DPPH and ABTS ${ }^{+}$methods have differentmechanisms and the antioxidant compounds in a sample can exhibit different chemical affinities, variation in its results is expected. According to the literature, the positive correlation between the RC and ABTS values is well recognised (Soares et al., 2008).
Equation 1 was used to adjust the experimental data presented in Table 2 through an estimate of nonlinear least squares. Table 3 shows the effect values (linear, interactive, and quadratic) of the independent variables investigated (time or $X 1$; temperature or $X 2$; extraction solvent concentration or $X 3$ ) for the three antioxidant potential evaluation methods.

Table 3 shows that of the three independent variables investigated $(X 1, X 2$, and $X 3)$, the extraction time $(X 1)$ had no significant effect on any of the investigated response ranges ( $p$-value $>$ $0.05)$. This information allows operating the system under conditions of greatest energy efficiency by extracting in the shortest possible time (within the investigated range) and enables generating statistically similar results.

\section{Table 3}

Effect estimates for the responses RC, DPPH and ABTS for the heat-assisted extraction according to the rotational central composite design

\begin{tabular}{|c|c|c|c|c|c|c|}
\hline \multirow[b]{2}{*}{ Factor } & \multicolumn{2}{|c|}{ RC (mg GAE g $\left.{ }^{-1}\right)$} & \multicolumn{2}{|c|}{ DPPH $\left(\mu \mathrm{mol}\right.$ Trolox $\left.\mathrm{g}^{-1}\right)$} & \multicolumn{2}{|c|}{ ABTS $\left(\mu\right.$ mol Trolox $\left.\mathrm{g}^{-1}\right)$} \\
\hline & Effect & $p$-value & Effect & $p$-value & Effect & $p$-value \\
\hline Mean & 9.40013 & $0.000003^{\mathrm{a}}$ & 21.78696 & $0.000000^{\mathrm{a}}$ & 171.9948 & $0.000001^{\mathrm{a}}$ \\
\hline \multicolumn{7}{|l|}{ Linear } \\
\hline$X 1$ & -0.78962 & 0.267819 & -0.19428 & 0.059183 & -10.2457 & 0.375036 \\
\hline$X 2$ & 1.66844 & $0.038471^{\mathrm{a}}$ & 0.14621 & 0.13422 & 59.3631 & $0.000918^{\mathrm{a}}$ \\
\hline$X 3$ & -1.55633 & $0.049423^{\mathrm{a}}$ & 0.04211 & 0.640623 & -24.0198 & 0.061802 \\
\hline \multicolumn{7}{|c|}{ Quadratic } \\
\hline$X 1$ & 0.90483 & 0.250765 & -0.0043 & 0.965219 & 22.2432 & 0.104173 \\
\hline$X 2$ & 1.93055 & $0.031936^{\mathrm{a}}$ & -0.04398 & 0.657844 & 20.1965 & 0.133901 \\
\hline$X 3$ & -2.20777 & $0.018453^{\mathrm{a}}$ & 0.36028 & $0.006824^{\mathrm{a}}$ & -39.5988 & $0.012707^{\mathrm{a}}$ \\
\hline \multicolumn{7}{|c|}{ Interaction } \\
\hline$X 1 . X 2$ & -0.10325 & 0.907457 & -0.24375 & 0.067443 & 0.8161 & 0.95554 \\
\hline$X 1 . X 3$ & -0.51425 & 0.567244 & 0.16525 & 0.186211 & -1.8819 & 0.897761 \\
\hline$X 2 . X 3$ & -0.18625 & 0.834095 & -0.22525 & 0.085924 & 19.2615 & 0.214913 \\
\hline
\end{tabular}

a Significant factor $(\alpha<0,05)$. 
The mathematical models were presented in Equations 4, 5, and 6. Although the linear effect of the solvent ratio variable presented a high $p$-value (0.06), it was maintained in the ABTS model. The significance of the generated mathematical models was verified, it was obtained that almost $90 \%$ of the experimentally obtained values for the RC and $\mathrm{ABTS}^{+}$method and more than $80 \%$ of the ones for the DPPH method is well explained by regression analysis (Table 4),

$\mathrm{RC}=9.977+0.834 X 2-0.778 X 3+0.832 X 2^{2}-1.237 X 3^{2}(4)$

$\mathrm{DPPH}=21.763+0.186 \times 3^{2}$

$\mathrm{ABTS}=192.90+29.68 X 2-12.01 X 3-24.63 X 3^{2}$

where $X 1, X 2$, and $X 3$ are the coded values for the variables time $(t)$, temperature $(T)$, and extraction solvent proportion $(S)$, respectively.

The models' coefficients cannot be associated with physical or chemical significance, as the experimental design is based on coded values. However, when a coefficient assumes a positive value, the increment in the variable value generates an increase in the response. Similarly, when a coefficient assumes a negative value, an increase in this variable will decrease the response.

$\mathrm{RC}$ and ABTS models present similar behaver, with the $X 2$ variable assuming positive values. It means that the temperature extraction increase may lead to a higher response. However, the negative value associated with the $X 3$ variable indicates that higher extraction solvent concentration can lead to lower responses. Although, the DPPH model showed several differences. The quadratic effect of the $X 3$ variable was the only significant one to the response and its positive value suggests that increases or decreases in the solvent concentration values lead to higher responses. However, because of the low regression coefficient value associated (0.186), the variance of the responses will be slight. On the $X 3$ variable case, the axial points are its range limit and, consequently, no more conditions can be tested.

Table 4

Fisher's F-test (ANOVA) for the RC, DPPH and ABTS response formats

\begin{tabular}{ccccccc}
\hline Response format & $\mathrm{SV}^{\mathrm{a}}$ & $\mathrm{SQ}^{\mathrm{b}}$ & $\mathrm{DF}^{\mathrm{c}}$ & $\mathrm{MS}^{\mathrm{d}}$ & F-calculated & F-tabulated \\
\hline \multirow{3}{*}{$\mathrm{RC}$} & Regression & 52.686 & 4 & 13.171 & 10.315 & 3,259 \\
& Residues & 15.323 & 12 & 1.277 & & \\
& Total & 68.009 & 16 & 4.251 & & \\
\hline \multirow{3}{*}{ DPPH } & Regression & 0.447 & 1 & 0.447 & 10.069 & 4.543 \\
& Residues & 0.666 & 15 & 0.044 & & \\
& Total & 1.114 & 16 & 0.07 & & 3.411 \\
& Regression & 21860.127 & 3 & 7286.709 & 16.149 & \\
\hline \multirow{2}{*}{ ABTS } & Residues & 5865.68 & 13 & 451.206 & & \\
& Total & 27725.8 & 16 & 1732.863 & & \\
& & & & & & \\
\end{tabular}

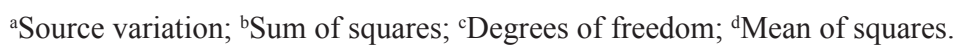

The response surface graphs (Figures 1, 2, and 3) were constructed from the variation of two variables within the experimental range, keeping the excluded variable constant at the centre of its experimental domain. 


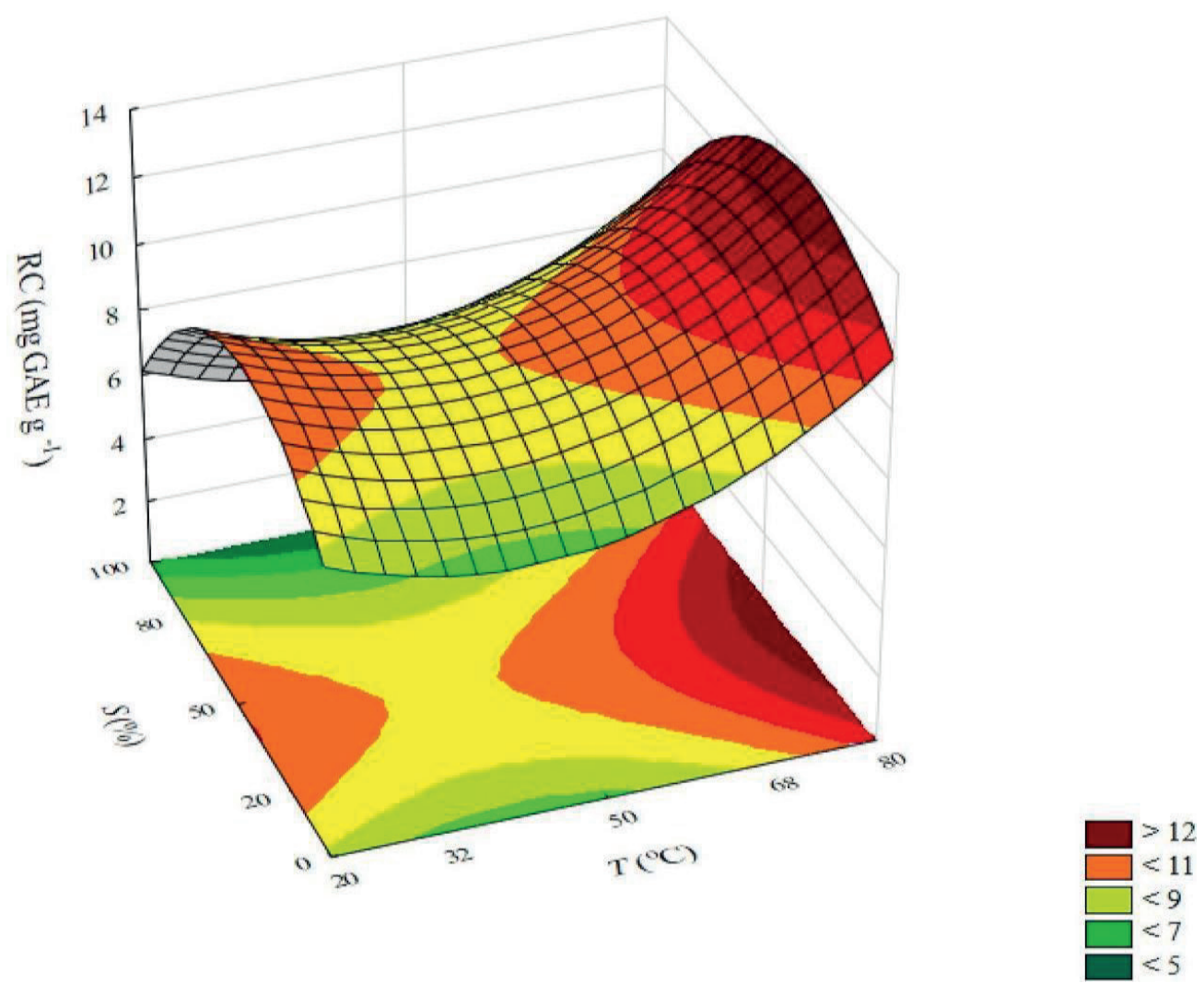

Figure 1. Theoretical three-dimensional response surface predicted with the second order polynomial of Equation 4, for the RC.

From Figure 1, it is observed that within the studied ranges, the condition that generated a maximum response in the extraction of phenolic compounds from beet stalk was high-temperature values (maximum tested) and intermediate values of solvent content (between 20 to 50\% approximately).

In Figure 2, the highest DPPH values are found in the tested axial points of the extraction solvent contents ( 0 and $100 \%$ ethanol). However, analysing the response axis scale (as well as Table 2), it is noted that the variation provided by these changes in the extraction condition is small (less than 0.9 mol Trolox $\mathrm{g}^{-1}$ ). This fact proves the low influence of the extraction conditions on the responses obtained by the method. 


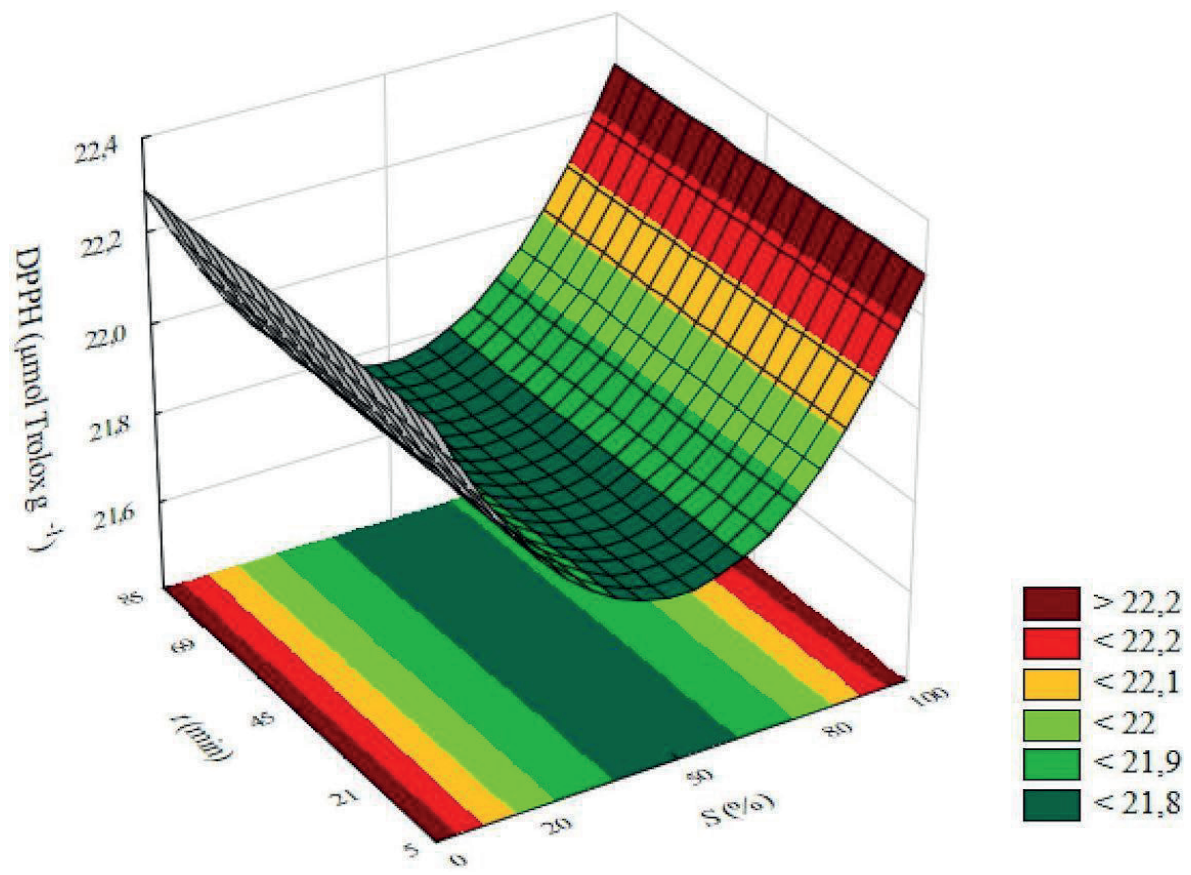

Figure 2. Theoretical three-dimensional response surface predicted with the second order polynomial of Equation 5, for the DPPH.

Figure 3 shows the highest ABTS responses at intermediate solvent values, approximately 40 maximum response was achieved at the upper axial point of the design, corresponding to $80^{\circ} \mathrm{C}$.

to $70 \%$ ethanol. For the temperature variable, the

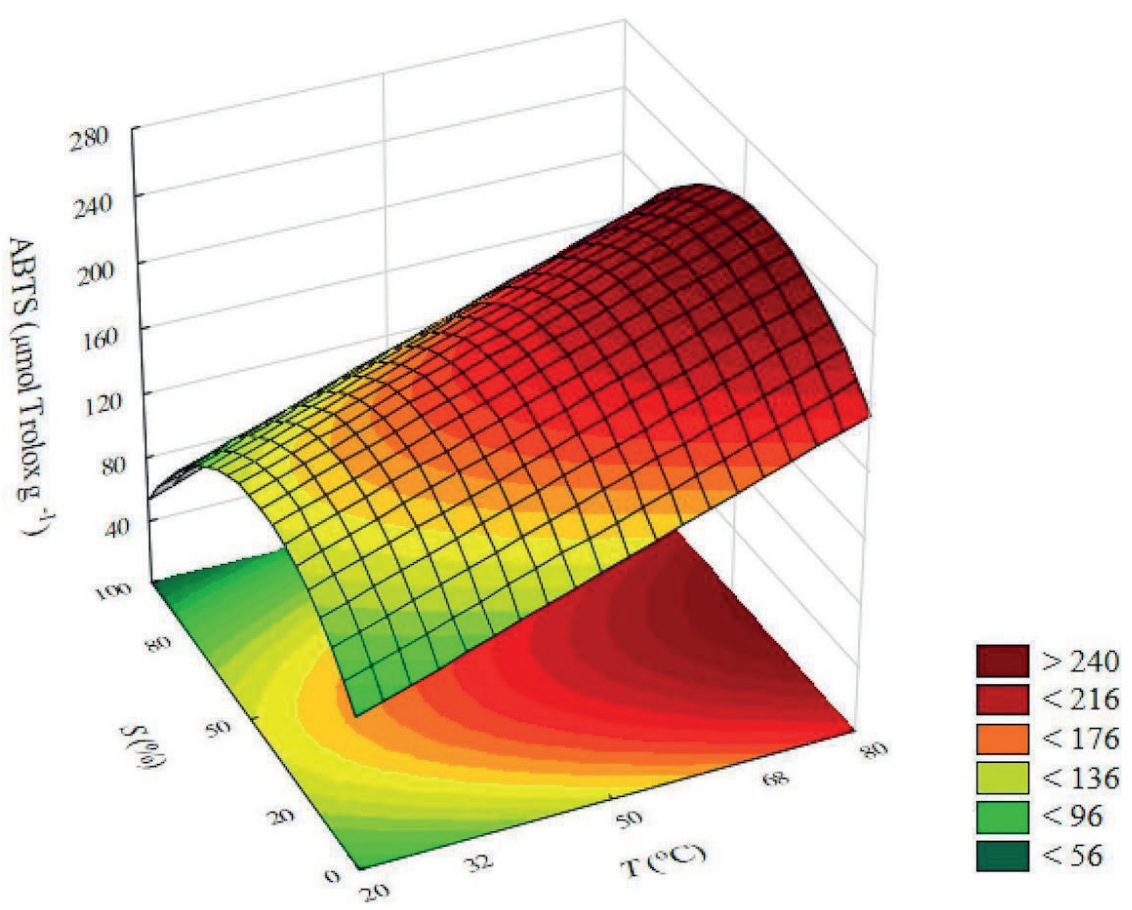

Figure 3. Theoretical three-dimensional response surface predicted with the second order polynomial of Equation 6, for the ABTS. 
Additional confirmation tests and extraction process optimisation

The overall analysis of the results of the three methods shows that the conditions that maximised the extraction of the compounds of interest were approximately $50 \%$ solvent content and $80{ }^{\circ} \mathrm{C}$, operating the system for short times $(5 \mathrm{~min})$. These conclusions were obtained by considering that no independent variable interfered with the DPPH response.

To confirm this data, the extraction process was performed again in conditions of maximum responses and the relative error between experimentally and mathematically predicted results were evaluated.

However, with such experimental design and study ranges, the optimal conditions for extracting compounds with antioxidant capacity from the beet stalk sample were not fully obtained.

For process optimisation, variables $X 1$ and $X 3$ were set at their optimal global values already determined by design (5 $\mathrm{min}$ and 50\% ethanol, respectively), while variable $X 2$ had an extended study range. Only the RC and ABTS $\bullet^{+}$antioxidant capacity were analysed at temperatures higher than the experimental design. The DPPH antioxidant responses did not present a representative variation under any of the planning conditions.

The confirmation of the mathematical models predicted results for the three response formats (RC, DPPH, and ABTS), and the RC and ABTS values obtained at higher extraction temperature conditions are presented in Table 5. At $80{ }^{\circ} \mathrm{C}$, the values of the three response formats (RC, DPPH, and ABTS) obtained were similar to those predicted by the generated mathematical models $(13.726 \mathrm{mg}$ GAE $\mathrm{g}^{-1}, 21.763 \mu \mathrm{mol}$ Trolox $\mathrm{g}^{-1}$ e $242.762 \mu \mathrm{mol}$ Trolox $\mathrm{g}^{-1}$, respectively). The relative error between them was $4.32 \%, 5.96 \%$, and $2.97 \%$ for RC, DPPH method, and ABTS $\bullet^{+}$method, respectively. These low values indicated a high agreement between experimentally and predicted responses and reinforces the previously validation of the proposed predictive models.

\section{Table 5}

Effect of the extraction temperature variation when the time and solvent proportion variables are set at their global optimal points

\begin{tabular}{|c|c|c|c|}
\hline $\begin{array}{l}\text { Temperature of } \\
\text { extraction }\left({ }^{\circ} \mathrm{C}\right)\end{array}$ & $\begin{array}{c}\mathrm{RC} \\
\left(\mathrm{mg} \mathrm{GAE} \mathrm{g}^{-1}\right)\end{array}$ & $\begin{array}{c}\text { DPPH } \\
\left(\mu \mathrm{mol} \text { Trolox } g^{-1}\right)\end{array}$ & $\begin{array}{c}\text { ABTS } \\
\left(\mu \mathrm{mol} \text { Trolox } \mathrm{g}^{-1}\right)\end{array}$ \\
\hline 80 & $13.157 \pm 0.111^{\mathrm{a}}$ & $20.539 \pm 1.033$ & $250.190 \pm 2.278^{\mathrm{a}}$ \\
\hline 85 & $12.999 \pm 0.050^{\mathrm{a}}$ & - & $251.104 \pm 7.731^{\mathrm{a}}$ \\
\hline 90 & $12.131 \pm 0.052^{\mathrm{b}}$ & - & $249.341 \pm 2.967^{\mathrm{a}}$ \\
\hline
\end{tabular}

*Values followed by the same letter do not differ by the Tukey test at $95 \%$ confidence.

For the $\mathrm{RC}$, it was observed that the $5^{\circ} \mathrm{C}$ increase did not cause significant differences in the response. However, the $10{ }^{\circ} \mathrm{C}$ increase in the extraction process led to the oxidation of some of the phenolic compounds present in the sample, resulting in a significantly decreased RC. Evaluating the ability of the extract to sequester $\mathrm{ABTS} \bullet^{+}$, it can be concluded that the increases in extraction temperature did not cause significant differences in ABTS values.
In general, for both antioxidant methods analysed, it is possible to work under conditions of high energy efficiency, that is, at $80{ }^{\circ} \mathrm{C}$, without a significant compromise in the obtained response. Therefore, the optimal conditions of extraction of compounds with antioxidant capacity of the beet stalks sample were obtained, and these were $5 \mathrm{~min}$, $80{ }^{\circ} \mathrm{C}$ and $50 \%$ ethanol. 


\section{Comparison with other studies}

Optimisation of the extraction process is one of the crucial stages towards the industrial implementation of recovering compounds with antioxidant capacity from beet stalk, thereby increasing its value as a source of natural antioxidants. Nevertheless, few studies have evaluated the content of these compounds in the beet residues. To the best of our knowledge, none of these studies have optimised the extraction of antioxidant compounds from this matrix, which hinder a comparison of the results. Therefore, the values obtained in this work will be compared with other residues from agri-food processing reported as sources of compounds with antioxidant capacity.

Previous research evaluated the RC of methanolic extracts of different agri-food residues obtained by ultrasonication. Carrot and white grape residues showed approximately 5.6 and 3 mg GAE g-1, respectively (Vodnar et al., 2017). In a similar study, RC values determined from ethanolic extracts obtained by heating under agitated conditions varied from 2.23 to $3.45 \mathrm{mg} \mathrm{GAE} \mathrm{g}^{-1}$ for cauliflower (Brassica oleracea L.) residue, 4.80 to $6.47 \mathrm{mg} \mathrm{GAE} \mathrm{g}^{-1}$ for garlic (Allium family) residue, and 12.87 to $16.12 \mathrm{mg} \mathrm{GAE} \mathrm{g}^{-1}$ for onion (Allium family) residue (Munir et al., 2018). In general, these comparisons highlight the superior recovery of phenolic compounds from the beet stalk investigated in the present study (13.157 $\left.\mathrm{mg} \mathrm{GAE}^{-1}\right)$.

Olive branches, a poorly valued by-product of olive groves, showed DPPH values of 5 to 8 mg Trolox $\mathrm{g}^{-1}$ for samples extracted with water, acidified water, and 1\% $\mathrm{NaOH}$ (Gullón et al., 2018). These values are close to the one determined in this study for beet stalk (5.4 mg Trolox $\mathrm{g}^{-1}$ ), a fact that reinforces the potential use of this residue compared to other residues studied in the literature.

Acerola (Malpighia emarginata D.C.) is a fruit recognised for its high antioxidant capacity. Its residue showed ABTS values of 291.91 Trolox $\mathrm{g}^{-1}$ in the hydro-acetonic extract (Caetano, Araújo,
Lima, Maciel, \& Melo, 2011), values very close to those obtained for beet stalk (still unused residue).

Other work assessed different agro-food residues and fruits for their $\mathrm{ABTS}^{\bullet^{+}}$antioxidant capacity after undergoing methanolic extraction. The recorded values were $17.07 \mathrm{mg}$ Trolox $\mathrm{g}^{-1}$ for orange residue, $11.63 \mathrm{mg}$ Trolox $\mathrm{g}^{-1}$ for strawberry residue, and $11.28 \mathrm{mg}$ Trolox $\mathrm{g}^{-1}$ for a mix of various vegetable residues (Castrica et al., 2019). In the current investigation, the optimal ABTS value for the beet stalk was $62.62 \mathrm{mg}$ Trolox $\mathrm{g}^{-1}$, which is higher than the previously investigated matrices.

The data presented emphasise the importance of the study of optimisation in industrial processes. Furthermore, the findings highlight the beet stalk as a promising source of antioxidant compounds.

\section{Conclusions}

The overall optimum conditions for extracting antioxidant compounds from beet stalk when using maceration are approximately $5 \mathrm{~min}, 80^{\circ} \mathrm{C}$ and $50 \%$ ethanol. The recovery of phenolic compounds with free radical scavenging capacity from beet stalk proves to be a sustainable and viable alternative to utilise and add value to this residue.

\section{References}

Ahmadian-Kouchaksaraie, Z., \& Niazmand, R. (2017). Supercritical carbon dioxide extraction of antioxidants from Crocus sativus petals of saffron industry residues: optimization using response surface methodology. The Journal of Supercritical Fluids, 121, 19-31. doi: 10.1016/j.supflu.2016. 11.008

Ainsworth, E., \& Gillespie, K. (2007). Estimation of total phenolic content and other oxidation substrates in plant tissues using Folin Ciocalteu reagent. Nature Protocols, 2(4), 875-877. doi: 10.1038/ nprot.2007. 102

Albuquerque, B. R., Prieto, M. A., Barreiro, M. F., Rodrigues, A., Curran, T. P., Barros, L., \& Ferreira, I. C. F. R. (2017). Catechin-based extract optimization obtained from Arbutus unedo L. fruits using maceration/microwave/ultrasound extraction techniques. Industrial Crops and Products, 95, 404415. doi: 10.1016/j.indcrop.2016.10.050 
Altemimi, A., Lakhssassi, N., Baharlouei, A., Watson, D. G., \& Lightfoot, D. A. (2017). Phytochemicals: Extraction, Isolation, and Identification of Bioactive Compounds from Plant Extracts. Plants, 42(6), 1-23. doi: 10.3390/plants6040042

Ameer, K., Bae, S. W., Jo, Y., Lee, H. G., Ameer, A., \& Kwon, J. H. (2017). Optimization of microwaveassisted extraction of total extract, stevioside and rebaudioside-A from Stevia rebaudiana (Bertoni) leaves, using response surface methodology (RSM) and artificial neural network (ANN) modelling. Food Chemistry, 229, 198-207. doi: 10.1016/j. foodchem.2017.01.121

Backes, E., Pereira, C., Barros, L., Prieto, M. A., Genena, A. Z., Barreiro, M. F., \& Ferreira, I. C. R. F. (2018). Recovery of bioactive anthocyanin pigments from Ficus carica L. peel by heat, microwave, and ultrasound based extraction techniques. Food Research International, 133, 197-209. doi: 10.1016/j. foodres.2018.07.016

Biondo, P. B. F., Boeing, J. S., Barizão, E. O., Souza, N. E., Matsushita, M., Oliveira, C. C.,... Visentaine, J. V. (2014). Evaluation of beetroot (Beta vulgaris L.) leaves during its developmental stages: a chemical composition study. Food Science and Technology, 34(1), 94-101. doi: 10.1590/S0101-20612014 005000007

Caetano, A. C. S., Araújo, C. R., Lima, V. L. A. G., Maciel, M. I. S., \& Melo, E. A. (2011). Evaluation of antioxidant activity of agro-industrial waste of acerola (Malpighia emarginata D.C.) fruit extracts. Ciência e Tecnologia de Alimentos, 31(3), 769-775. doi: 10.1590/S0101-20612011000300034

Castrica, M., Rebucci, R., Giromini, C., Tretola, M., Cattaneo,D.,\&Baldi,A.(2019). Totalphenoliccontent and antioxidant capacity of agri-food waste and byproducts. Italian Journal of Animal Science, 18(1), 336-341. doi: 10.1080/1828051X.2018.1529544

Costa, A. P. D., Hermes, V. S., Rios, A. O., \& Flôres, S. H. (2017). Minimally processed beetroot waste as an alternative source to obtain functional ingredients. Journal of Food Science and Technology, 54(7), 2050-2058. doi: 10.1007/s13197-017-2642-4

Gullón, B., Gullón, P., Eibes, G., Cara, C., Torres, A., López-Linares, J. C.,... Castro, E. (2018). Valorization of olive agro-industrial by-products as a source of bioactive compounds. Science of the Total Environment, 645, 533-542. doi: 10.1016/j. scitotenv.2018.07.155

Ilaiyaraja, N., Likhith, K. R., Babu, G. R. S., \& Khanum, F. (2015). Optimization of extraction of bioactive compounds from Feronia limonia (wood apple) fruit using response surface methodology (RSM). Food Chemistry, 173, 348-354. doi: 10.1016/j. foodchem.2014.10.035

Kumar, V., Kushwaha, R., Goyal, A., Tanwar, B., \& Kaur, J. (2018). Process optimization for the preparation of antioxidant rich ginger candy using beetroot pomace extract. Food Chemistry, 245, 168-177. doi: 10.1016/j.foodchem.2017.10.089

Lemes, A. C., Álvares, G. T., Egea, M. B., Brandelli, A., \& Kalil, S. J. (2016). Simultaneous production of proteases and antioxidant compounds from agroindustrial by-products. Bioresource Technology, 222, 210-216. doi: 10.1016/j.biortech.2016.10.001

Mensor, L. L., Menezes, F. S., Leitão, G. G., Reis, A. S., Santos, T. C., Coube, C. S., \& Leitão, S. G. (2001). Screening of Brazilian plant extracts for antioxidant activity by the use of DPPH free radical method. Phytotherapy Research, 15(2), 127-130. doi: $10.1002 /$ ptr.687

Munir, A., Sultana, B., Bashir, A., Ghaffar, A., Munir, B., Shar, G. A.,... Iqbal, M. (2018). Evaluation of antioxidant potential of vegetables waste. Polish Journal of Environmental Studies, 27(2), 947-952. doi: $10.15244 /$ pjoes/69944

Nistor, O. V., Seremet, L., Andronoiu, D. G., Rudi, L., \& Botez, E. (2017). Influence of different drying methods on the physicochemical properties of red beetroot (Beta vulgaris L. var. Cylindra). Food Chemistry, 236, 59-67. doi: 10.1016/j. foodchem.2017.04.129

Re, R., Pellegrini, N., Proteggente, A., Pannala, M. Y., \& Rice-Evans, C. (1999). Antioxidant activity applying an improved ABTS radical cation decolorization assay. Free Radical Biology \& Medicine, 26(9), 1231-1237. doi: 10.1016/s0891-5849(98)00315-3

Soares, M., Welter, L., Gonzaga, L., Lima, A., Mancini, J., Fo., \& Fett, R. (2008). Avaliação da atividade antioxidante e identificação dos ácidos fenólicos presentes no bagaço de maçã cv. Gala. Ciência e Tecnologia de Alimentos, 28(3), 727-732. doi: 10.1590/S0101-20612008000300032

Tran, T. N., Athanassiou, A., Basit, A., \& Bayer, I. S. (2017). Starch-based bio-elastomers functionalized with red beetroot natural antioxidant. Food Chemistry, 216, 324-333. doi: 10.1016/j.foodchem.2016. 08.055

Vodnar, D. C., Calinoiu, L. F., Dulf, F. V., Stefãnescu, B. E., Crisan, G., \& Socaciu, C. (2017). Identification of the bioactive compounds and antioxidant, antimutagenic and antimicrobial activities of thermally processed agro-industrial waste. Food Chemistry, 231, 131140. doi: 10.1016/j.foodchem.2017.03.131 